\title{
Dyke Davidhoff Masson Syndrome Presenting in Adulthood: A Case Report
}

\author{
Monika Jawanjal, Nilesh Walke, Archana Bhate, Avinash Jawanjal \\ Padmashree Dr. D Y Patil Hospital \\ Email: drmonika257@gmail.com, nileshsukhdeo83@yahoo.com, drmona257@gmail.com, \\ swayam.jawanjal@gmail.com
}

Received 21 March 2015; accepted 26 May 2015; published 29 May 2015

Copyright (C) 2015 by authors and Scientific Research Publishing Inc.

This work is licensed under the Creative Commons Attribution International License (CC BY). http://creativecommons.org/licenses/by/4.0/

(c) (i) Open Access

\begin{abstract}
Dyke Davidhoff Masson syndrome (DDMS) was first described by Dyke Davidhoff and Masson in 1933 in a series of 9 patients [1]. It's a very rare condition presenting in childhood ranging from infancy to late adolescence [2]. It is characterised by cerebral hemiatrophy, unilateral ventriculomegaly, calvarial thickening, skull and facial asymmetry, sometimes even contralateral hemiplegia in childhood and seizures [2]. An adult presentation is seen in late adolescence or teen age. However in literature the latest presentation reported so far is at 19 years of age [3]. We report a case of Dyke Davidhoff Masson syndrome who presented first time at the age of 28 years which is probably the oldest presentation of this rare entity reported in the literature.
\end{abstract}

\section{Keywords}

Dyke Davidhoff Masson Syndrome, Cerebral Hemiatrophy, Childhood Hemiplegia

\section{Case Report}

A 28 years old male, right handed person, working as a labourer, hailing from Uttar Pradesh (India) was brought to the Emergency Department (ED) with one episode of generalised tonic-clonic convulsions around half an hour before presenting to ED. The patient had just reached the workplace and was about to start the work when he suddenly got generalised tonic-clonic convulsions at around 9 am as witnessed by his co-workers. The convulsions lasted for around $2-3$ minutes and it was associated with up rolling of eyeballs and frothening of mouth. The patient was unconscious for about 10 minutes after convulsions as per informed by the associates. The patient was drowsy on presentation. Clinically, his GCS was 10/15, Bilaterally plantars were extensor and all the deep tendon reflexes were brisk in both upper and lower limbs. There was no evidence of any cranial nerve involvement on presentation. The patient was treated on the lines of GTCS and was loaded with intravenous Phenytoin as per weight (20 mg/kg body weight). His basic investigations were sent and patient was 
immediately taken up for CT brain for further evaluation.

The blood reports were as follows:

Hemoglobin $=14 \mathrm{~g} \%$, Total Leucocyte count $=6000 /$ cubic mm. Platelets $=2.4$ lacs $/$ cubic mm

Serum Sodium $(\mathrm{Na})=136$, Serum Potassium $=4.0$, Serum Chloride $=100$

Serum Calcium $=8.2 \mathrm{mg} \%$ Serum Creatinine $=0.8 \mathrm{mg} \%$

The CT Brain was suggestive of left sided cerebral hemiatrophy with epsilateral enlargement of lateral ventricle (Ventriculomegaly); features suggestive of Dyke Davidhoff Masson Syndrome (DDMS) (See Figure 1 \& Figure 2). MRI brain with MR angiography was done to confirm the diagnosis and delineate the arterial system after stabilization.

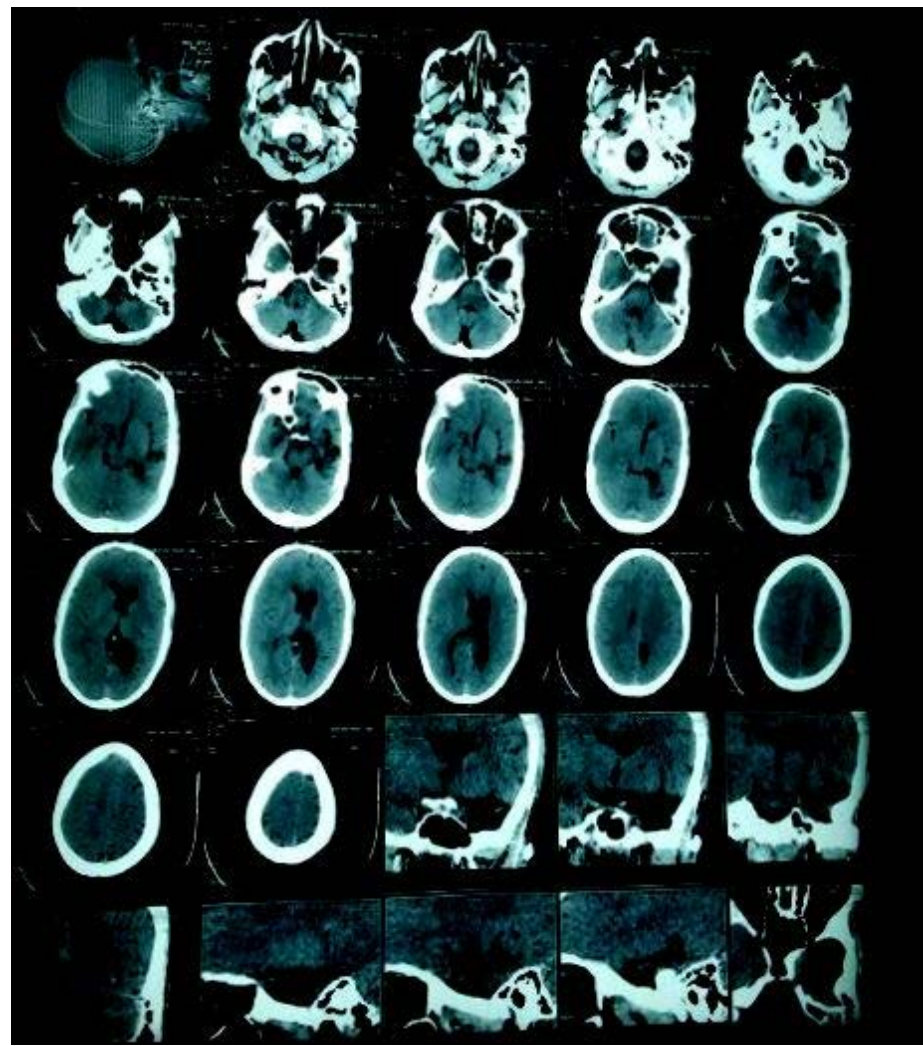

Figure 1. CT scan Brain showing cerebral hemiatrophy with unilateral (Left) ventriculomegaly.

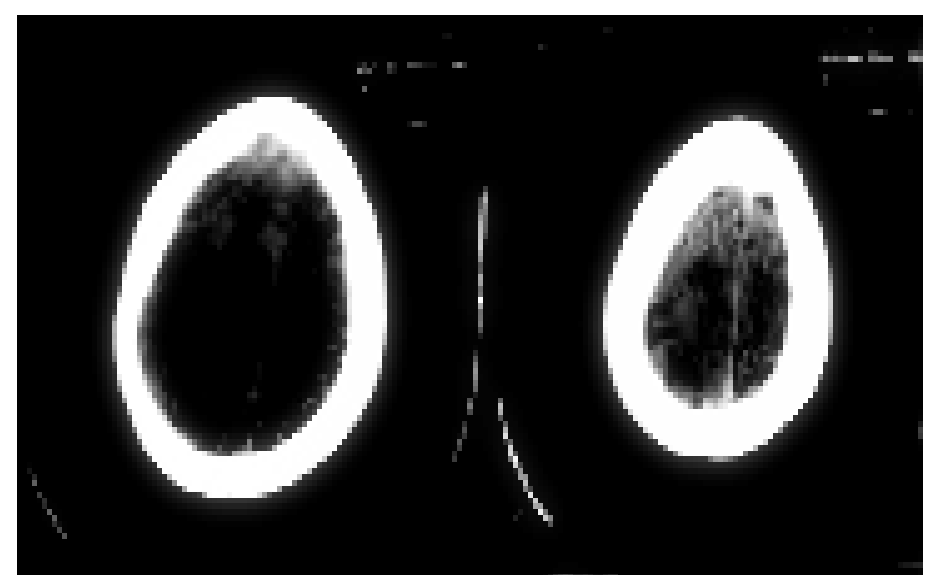

Figure 2. CT brain image showing left cerebral hemiatrophy. 
However after the patient regained his consciousness, there was no neurodeficit.

The patient was put on anticonvulsants and was discharged after neurologist opinion.

The EEG was also done which showed epilepti form focus in the left cerebral hemisphere.

The unusual presentation of our patient at the age of 28 years without any neurodeficiet despite being a right handed person and having left cerebral hemiatrophy makes it a remarkable case.

Discussion: Dyke Davidhoff Masson syndrome is a very rare condition presenting in infancy or early childhood generally. Some cases with late presentation up to the age of 19 years have been reported [3]. However first manifestation at the age of 28 years or more has not been reported so far in literature.

Clinically the patients present with:

1) Hemiplegia in childhood

2) Seizures

3) Skull and facial asymmetry [1]-[4]

Male sex and left hemispheric predisposition to vascular impairment has been reported in this syndrome [5]. Clinical [presentation is variable but seizures is the most common clinical manifestation. Hemiplegia presenting in childhood one must suspect DDMS [6]. Nystagmus, impairment of fixation and pursuit may be present depending on the affection of functionally related cortical or subcortical areas [6].

Congenital as well as acquired causes have been recognised [2].

Congenital causes include:

1) Cerebral hemispheric hypoperfusion

2) Brain Dysgenesis

3) Septo-optic dysplasias

4) Encephalocraniocutaneouslipomatoses

5) Shimmelpenning syndrome

6) Struge Weber syndrome

7) Silver Russel syndrome

Acquired causes include:

1) Periventricular leucomalacia

2) Cerebral hemorrhage

3) Trauma during Forcep delivery

4) Cerebral Infections

5) Cerebral Infarction

6) In adults, recurrent thromboembolic episodes in the same arterial territory in Rheumatic valvular heart disease

Proper history taking, thorough clinical eavaluation and radiological imaging like CT and MRI brain can confirm the diagnosis of this rare syndrome. Prognosis is better if the symptoms appear after 2 years of age and in absence of recurrent or prolonged seizures. Children with inractable disabling seizures and hemiplegia are the potential candidates for hespherectomy with success rate of around $85 \%$ in carefully selected patients [7].

\section{Conclusion}

Dyke Davidhoff Masson syndrome is a rare clinical entity particularly first presentation in adulthood is very rare. Our patient presented first time at the age of 28 years which is the oldest presentation reported so far. Early diagnosis and appropriate treatment forms the key for the management of this rare disabling condition.

\section{References}

[1] Dyke, C.G., Davidoff, L.M. and Masson, C.B. (1933) Cerebral Hemiatrophy with Homolateral Hypertrophy of the Skull and Sinuses. Surgery, Gynecology \& Obstetrics, 57, 588-600.

[2] Koirala, et al. (2012) Dyke Davidhoff Masson Syndrome. Journal of Nobel Medical College, 1, 84-86.

[3] Zilkha, A. (1980) CT of Cerebral Hemiatrophy. American Journal of Roentgenology, 135, 259-562. http://dx.doi.org/10.2214/ajr.135.2.259

[4] Singh, P., Saggar, K. and Ahluwalia, A. (2010) Dyke-Davidoff-Masson Syndrome: Classical Imaging Findings. Journal of Pediatric Neurosciences, 5, 124-125. http://dx.doi.org/10.4103/1817-1745.76108

[5] Unal, O., Tombul, T., Cýrak, B., Anlar, O., Incesu, L. and Kayan, M. (2004) Left Hemisphere and Sex Dominance of 
Cerebral Hemiatrophy (Dyke-Davidoff-Masson Syndrome). Clinical Imaging, 28, 163-165. http://dx.doi.org/10.1016/S0899-7071(03)00158-X

[6] Pressler, R.M., Binnie, C., Cooper, R. and Robinson, R. (2007) Neonatal and Paediatric Clinical Neurophisiology. Churchill Livingstone Elsevier, Amsterdam, 111-154.

[7] Solomon, G.E., Hilal, S.K., Gold, A.P. and Carpter, S. (1970) Natural History of Acute Hemiplegia of Childhood. Brain, 93, 107-120. http://dx.doi.org/10.1093/brain/93.1.107 